\title{
تحليل الأخطاءالنحوية في مقدمة خطبة الجمعة
}

\section{(دراسة السياقية)}

Abdul Aziz Al Khumairi

Universitas Islam Negeri Sunan Kalijaga, Yogyakarta, Indonesia

Email : Azizalkhumairi@gmail.com

\begin{abstract}
This research is a continuation of the research that has been done before, except that the theme carried out in this study is different. The aim is that more and more references to research in this theme will be the lower level of difficulty of Non-Arabic speakers in speaking Arabic, especially the mistakes of Nahwu (Syntacs). Determination of location became important in this study, researchers took boarding school respondents in the city of Bengkulu who excelled in terms of Arabic, namely Darussalam Islamic Boarding School located in the City of Bengkulu. The approach used is qualitative and the data are like numbers to reinforce conclusions. His method is descriptive analysis, by describing all data with explanations in the form of words. The method of data collection is by interviewing, unstructured dialogue, and recording using audio media. The results showed that there were 56 conversational errors in Scientific Sermon activities, there were 38 syntactic errors, meaning that around $68 \%$ specific language errors occurred in syntax, while the cause of errors was focused on 3 big points, first: Speakers underestimated rules, the error rate was 18\% second: Speakers do not know the rules, the rate of occurrence of errors is $34 \%$, third: Interverence rate of occurrence of errors is $18 \%$.
\end{abstract}

\section{Keywords: Error Analysis, Error, and Syntax}

$$
\begin{aligned}
& \text { إلى رأي العالم اللغوي السابق، نرى أن رأيه } \\
& \text { معنى التسامح الكلي يتجلى من المسامح على الحذر من الخطأ محال، وإن } \\
& \text { خلال قول Brook Nelson،أن أول الأمر ان الجهد إليه وسيما. وذلك لأن الخطأ } \\
& \text { نخو الأخطاء وجوب الخنر، وهو أن بدهي الوقوع في عملية تعلم اللغة الأجنبية } \\
& \text { يأخذ المتكلم زمام الحذر الحاتم قبل شروعه ايعني اللغة العربية. }
\end{aligned}
$$

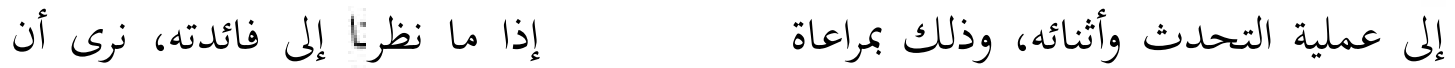

$$
\begin{aligned}
& \text { القواعد اللغوية المتعلقة به، وإن كان الخطأ أمر مسموح ل لأنه يبلب فائدة } \\
& \text { الخذرمنها ضئيلا، ال يسع الحذر.وقريب ترجع إلى المعلم، وهو كونه رد من ردود }
\end{aligned}
$$


أيضا يستخدم في غير الأعيان . هذا المثال البسيط قد حدث شأنه في كثير من الأحيان ، ولا يككن للمعلم القيام بالمعالجة

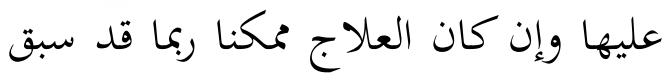

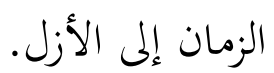

مثال آخر الذي تتجلى عنه ظاهرة الأخطاء اللغوية ، ما حدث بنال بسبب

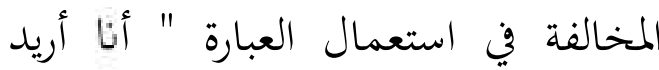

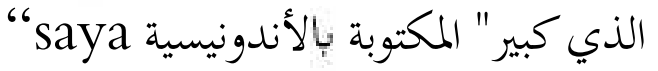
ingin yang besar."

شئ مطلوب ، والطالب مشيرا إلى المعين

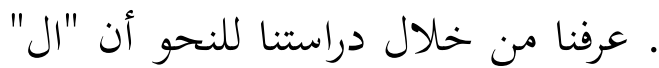
للتعريف ، ولاتستعمل إلا للمعرفة. ولذلك استعمال "الذي" قبل مجيء كلمة "كبير "عبث. المفروض أن يأتي المتحدث لئية

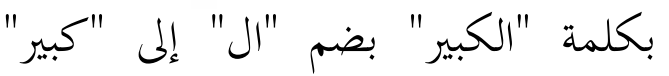
لأن الشيئ المطلوب معروف.

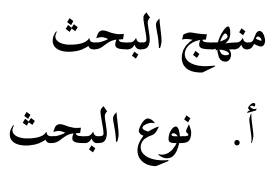

فعلية(feedback)ليكون مقياسا للتعرف على مدى كفاية الطالب. وكذلك ليكون مدخال إلى تجديد طرق تدريس اللغة العربية. لايكتفي الأمر إلى حده الأدنى

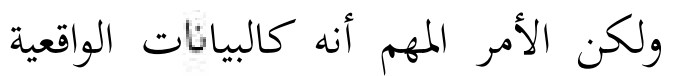
التي تساعد على قيام البحوث الآتية فيها' .

هذا الموقف ، تحدث كثيرا في معهد دار السلام التي تقع بلمدينة بنجكولو، نضرب مثالا لتلك الظاهرة في

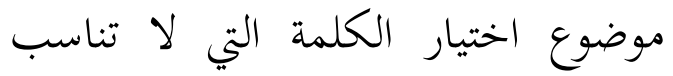
بالمقام ، تبدو في كلمة "قديم جدا" معبرا

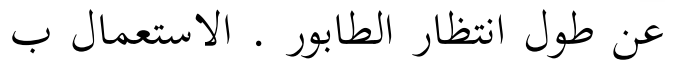

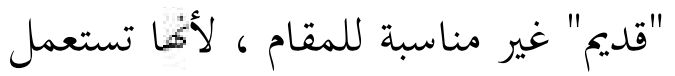

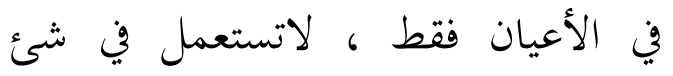

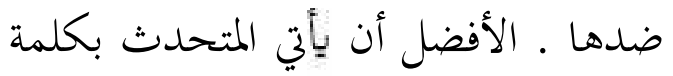

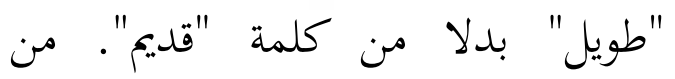
جانب أن "طويل "مناسب للمقام، وهو

${ }^{1}$ Ed. Kenneth Croft. 1980.

Contrastive Analysis, Error Analysis and Interlanguage : Three Phases of One Goal, (No Place Publication. Jurnal Reading on English as a Second Language for Teacher and Teacher Trainers, edisi 2. Indihati, Dian. 30 Oktober 2014. Pukul, 15.09 WIB. Analisis Kesalahan Berbahasa. 
فيه على صورة تقارير صريحة جلية ومقبولة عند المستطلعين جميعا.' و و أما معطيات البحث التحليلي التراكيب الكالامية من الكلماتوالعبارات والجمل الكالامية التي سوف ستبحث في معهد دار السالمبنجكولو و المدرسة العالية بنجكولو

هذا البحث لا يستغني في حد

ذاته إلى المعطيات الحرفية التي تشتمل

على كلمات أو عبارات أو جمل، ولكن استعان الباحث بالمعطيات الإحصائية الكمية وquantitative approch) مدى ما وصلت الأخطاء التي يوجهها الطلاب الغرض من أجلها التدعيم على البيانات والتزويد عليها والتسهيل على استخراج الخلاصة'.

2 Lexy, Moleong, Metodologi Penelitian Kualitatif. Bandung: PT Remaja Rosdakarya, 2005, hlm. 10

${ }^{3}$ Anas Sudjiono, Pengantar Statistik Pendidikan, Jakarta: Rajawali Press, 1991, hlm. 40
يدخل البحث ضمن البحوث

الميدانية(field research) أي ما تكتب

مستخدمة نتائج أبيانات المعطيات الحاصلة من ميدان البحث.

وكذا يستخدم البحث طريقة وصفية (deskriptif), وذلك بدمج ثلاثة عناصر المتعلقة المكونة من البحث التحليلي من عنصر التعرف على المعطيات، وعنصرالبيان والشرح على المعطيات، وعنصر الخالصة . ويستخدم الكيفية النوعية qualitative

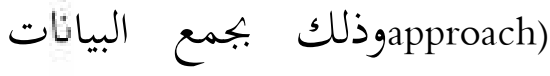
الواقعية الموجودة في الحال أو المكان بطريقة المالاحظة عليها ثم القيام بدراستها ويمللها تم يفسرها ويشرحها، وفي الأخير كتابة الخالصة من عمليته، وهذا مايسمى بالملدخل الاستقرائي (inductive approach). واستخدام مدخل استقرائي في البحث يهدف إلى إحضار الوقائع المحلية ما هي كالبيانات أو المعطيات 
فيها، ومواد الدراسة و

تقويمها

Y. التلاميذ، يتركز البحث

على التلاميذ بالمرحلة

العالية بفصولا المختلفة

من الكلمات الصادرة من

خطبهم مما يبحث فيها

الباحث . ووسيلة العينة

تخدم الباحث بالمكم

$$
\text { على الكل من الجزء. }
$$

ج وسائل جمع البيانات

1. الحوارات، وهي تسمى

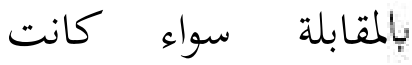

المقابلة موجهة مأو

عكسها، وكذا بوسيطة

المحادثة باليومية

العربية بعهددار السلام

بنجكولو

4 Suharsimi., Prosedur Penelitian

Suatu Pendekatan Praktik, Jakarta: Bina Aksara, 1984, hlm. 10
المعطيات التي يمتلكها نوع البحث

الوصفي هي التراكيب الكلامية من

الحروف والكلمات والجمل من الخطأ

الإنشائي اللغوي لدى الطلاب. العلة

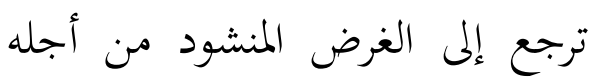

تكوين البحث الوصفي وهي تجهيز

المعطيات الواقعية بطريق مرتب سهل

الوصول إلى الفهم . ومضمون هذا لهانيا

المتوى قد تمت محاولة إدماج

القانونين البحثين في معرض نقاشه في

نطاق منهج المقارن. حيث أشار إلى لفان

المنهجين

الوصفين(deskriptif)والتحليلي

في البحث. (analysis)

ب.مصدر البيانات الأساسية

تصدر البيانات والمعلومات من

$$
\text { المصادر الآتية: }
$$

1. مدرس اللغة، يعرف منه

الباحث عن عملية تعليم

اللغة العربية وتعلمها،

ومعرفة الطريقة المستخدمة 
: الأخطاء اللغوية التي تقع من

جانب علم النحو.(syntacs).

هـ عينية البحث

يركز البحث إلى الكلمات أو لئل

الجمل أو العبارات التي يتحدث عنها

الطلاب باللغة العربية في معهد

دارالسلام بنجكولو في برامج

المحاضرات(presentations) أخذ

الباحث نحو ستا وخمسين حوارا في

$$
\text { المحاضرات. }
$$

ثم تأتي بعد التحليل طريقة

الإحصاء، استعان الباحث بالمعيار

المئوي المتواضع البسيط في استخراج

النسبة المئوية ليتوصل بهما إلى معرفة

نتائج البحث من نقاط اختلاف

درجة انتشار الأخطاء . وطريقة

الإحصاء هي : : عدد الأخطاء

المتعلقة بقاعدة معينة يقسم بعدد

مجموع الأخطاء الكلية، ثم تضرب

نتيجة العملية ـيظهر الحساب جليا:

السابقة في المئة في النحو الآتي:
Y. الملاحظة، وتسمى أيضا

بطريقة المشاهدة. وهي

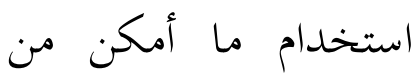

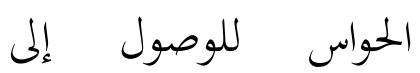

حقيقة وإدراكها

وصفها وصفا دقيقا.

r. الاختبار، وكانت تسهم

سهما عظيما، وذلك

بطرح الأسئلة على

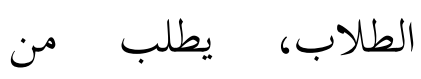

الطلاب تعبير المطلوب

بالعربية. و وأخيرا مناقشة

كلامهم

آخرين.

\section{د. ت ت مديد المسألة}

اقتصر الباحث على نوع من من

أنواععلوم قواعد اللغة العربية لتكون

مبدءا في كتابة البحث، بحيث تكثر

فيها فيما يتعلق بالموضوع وهي

الأخطاء الكلامية، وإليك البيان عنها 


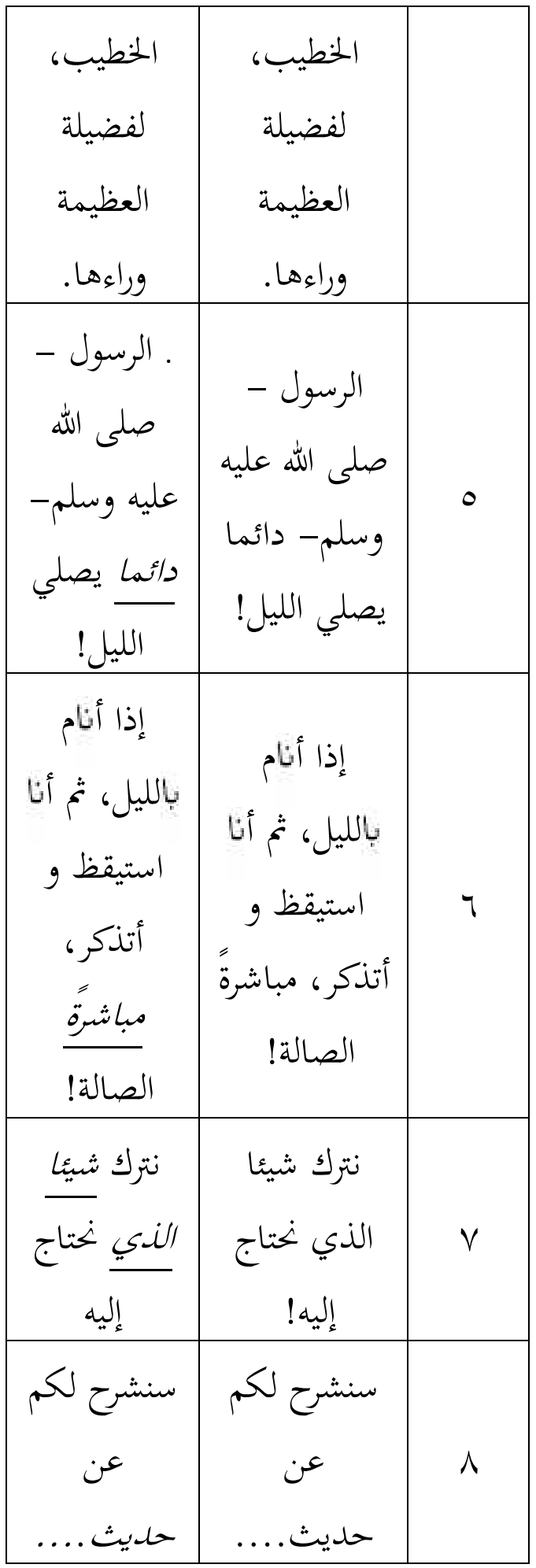

$$
\text { عدمد ألخطاء }
$$

عرض البيانات الحخطاء اللغوية في

\begin{tabular}{|c|c|c|}
\hline الحذطأ & الجمملة & الرقم \\
\hline أن علىيب البد قدب عقر & أن على عيب قلب البد & 1 \\
\hline الختى يدركب & الختى يدرك وثمب قدره & $r$ \\
\hline 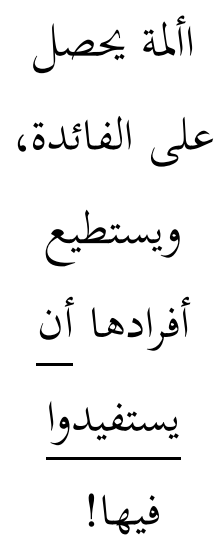 & على ألمة يكصل الفائدة، & $r$ \\
\hline أن يستمع & أن يستمع & $\varepsilon$ \\
\hline
\end{tabular}

القواعد النحوية(Errors Syntac) 
VOLUME.3 NO.1 JUNI 2019

ISSN : 2599-0659

E-ISSN: 2657-0742

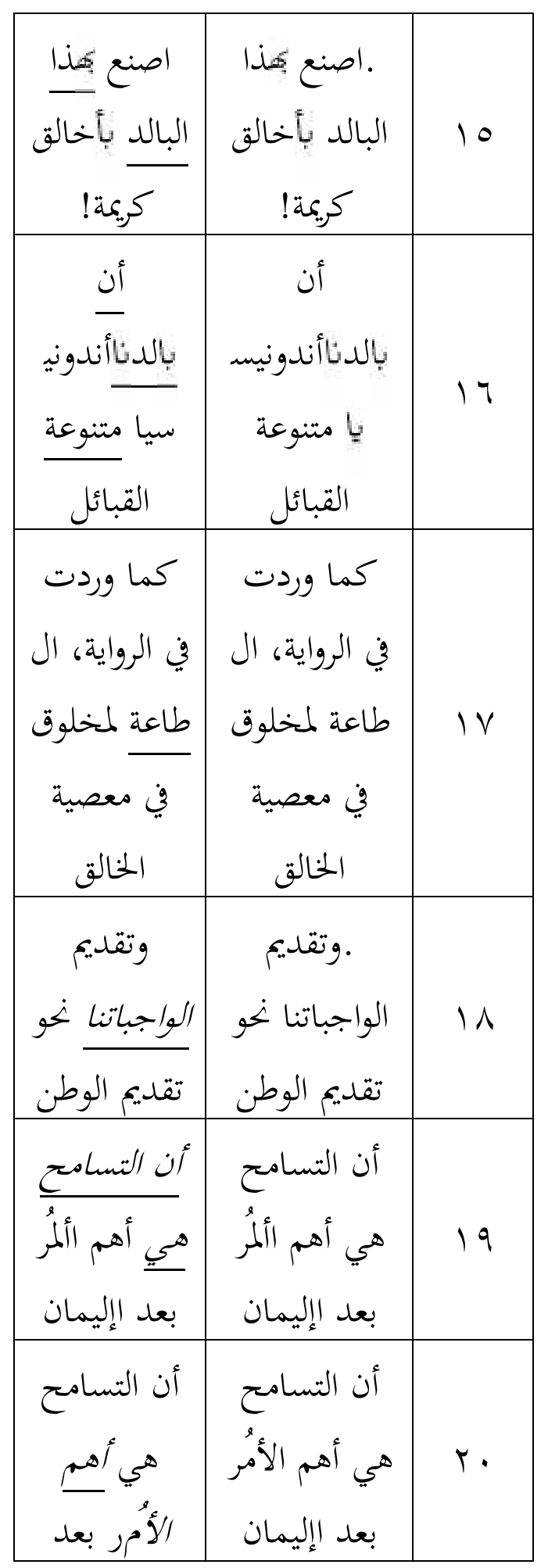

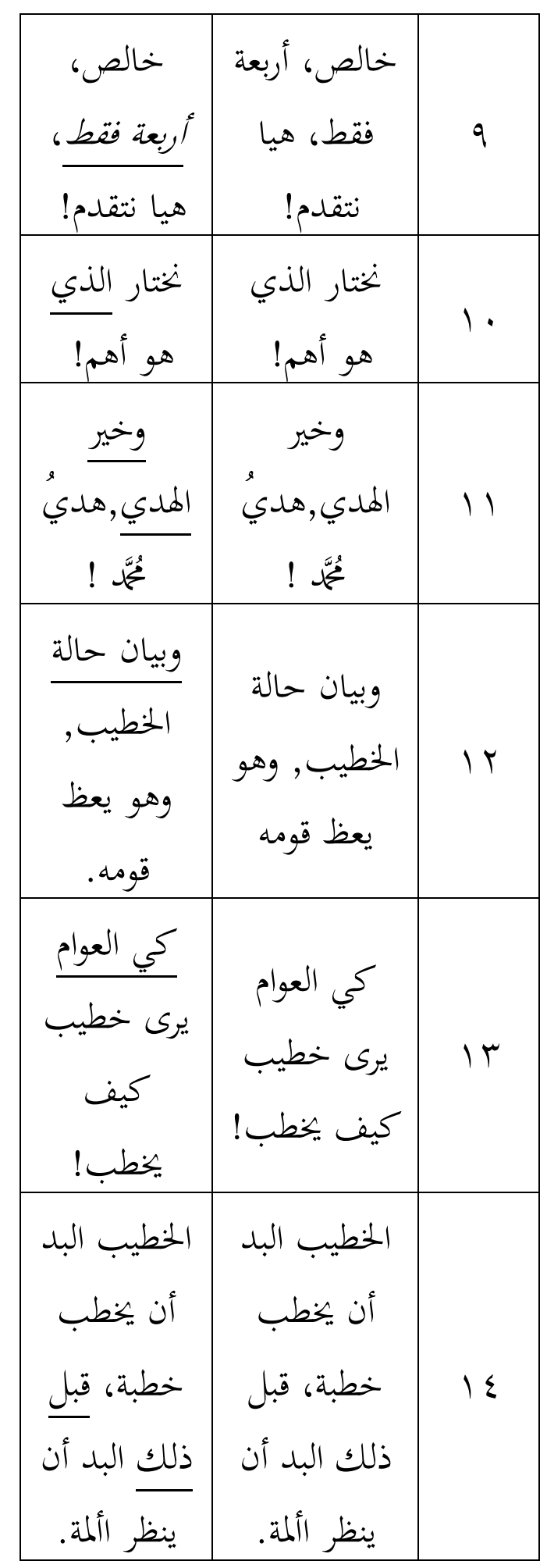




\begin{tabular}{|c|c|c|}
\hline •يكون قير & •يكون قير & \\
\hline الحمداد ريها & الحماد ريها & rT \\
\hline خبيسة & خبيسة & \\
\hline
\end{tabular}

عدم المغعول به للفعل المتعدي الحنطأ

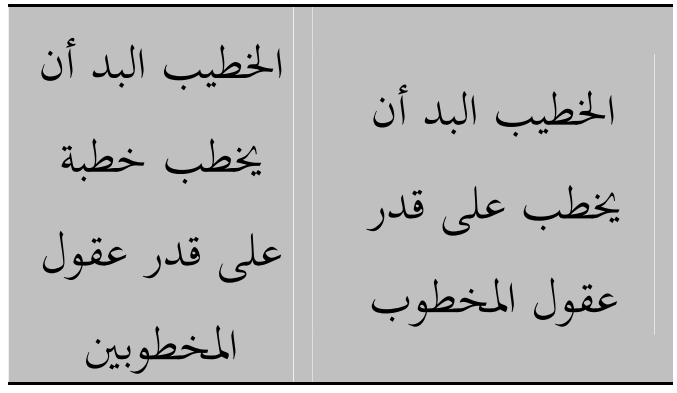

ورود الفعل المتعدي "خطب - يخطُب" من غير مفعوله غلط وخطأ من حيث ردو قاعدة النحو. لمخالفة قواعد وضوابط الأفعال المتعدية من لزوم الإتيان بالمفعوالت .على المتحدث أن يأتي بالمفعول به 6 نحو :أن يخطب مقالة" 6 أو أن يأتي بالفعول المطلق ، نهو: "أن يخطب خطبة" وغيرهما تطبيقا للقاعدة الالزمة، وإن وردت الإستثناءات على جواز الحذف ، إلا أنه وارد في علم البالغة كة ومقاممنا في علم النحو . والسبب منه

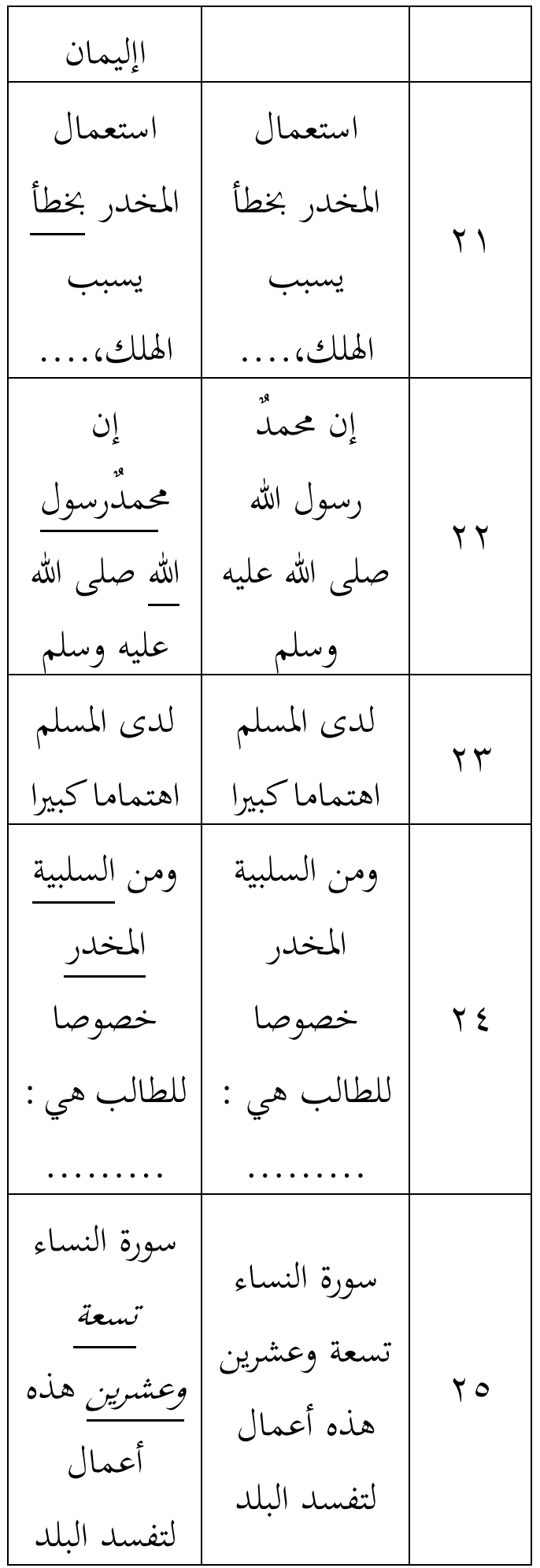


أصبحت "الأمة تحصل على....". يقع

فيها كثير من المتحدثين لعدم ممارستهم في

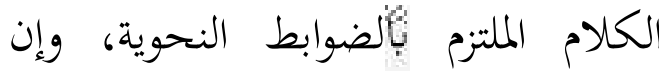

سبقت إليه معرفة علامة التذكير والتأتيث • وحرف "فيها" من الجملة "أن يستفيدوا فيها" غير مناسبة للكلمة. ذكر في كثير لئه من القواميس العربية أن كلمة "استفاد-

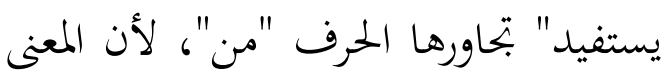
طلب الفائدة في آلخر. ولعل السبب من وقوع الخطأ فيها عدم معرفة المتحدث للحروف المناسبة للكلمات

مخالفة المعطوف إعراب المعطوف عليه

\begin{tabular}{|c|c|}
\hline الصواب & الخطأ \\
\hline حتى يدرك & حتى يدرك \\
\hline الخطيب قد ره & الخطيب قد ر \\
\hline وثمرته & ثمرته \\
\hline
\end{tabular}
طلب الفائدة من آلخر، وليس المعنى

تساهل المتحدث عن الإتيان بالمفعول ،

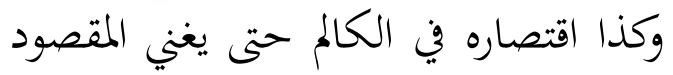
إلى المخاطب . أما كلمة "المخطوب" فإنها تقع خطأ ، لأن الكلمة التي وقعت الماطت سابقة مضافا على شكل جمع التكسير ،

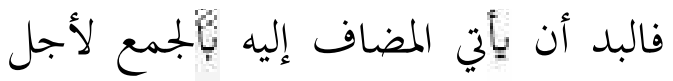
التناسب بينهما . وأصبحت الجملة الصحيحة "أن يخطب مقالة على قدر عقول المخطوبين." تذكير الفعل حقه تأنيث واستعمال الحروف غير المناسبة للكلمة

\begin{tabular}{|c|c|}
\hline الصواب & الخطأ \\
\hline الأمة تحصل على & لأمة يكصل على \\
\hline الفائدة، ويستطيع & لفائدة، ويستطيع \\
\hline أفرادها أن & أندا مأٔ. \\
\hline يستفيدوا منها! & يستفيدوا فيها! \\
\hline
\end{tabular}

كلمة "الأمة" مؤنثة، لاتصالها

وقعت كلمة "قدره" مفعولابه، وعلامة

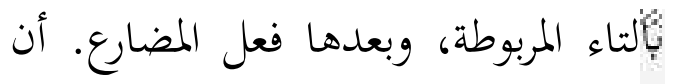
يكون الفعل للفاعل المؤنث مؤنثا الجملة

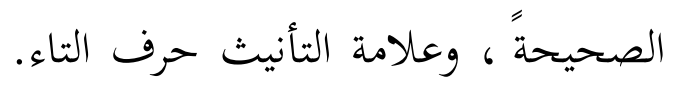


النحاة على نصب الأسماء مبتدً في أول الجملة إلا لعامل محذوف. ويصير إتيانه متقدما عبثا وخخالفا للقواعد النحوية.

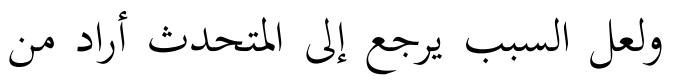

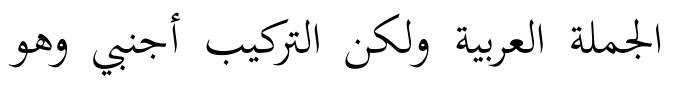

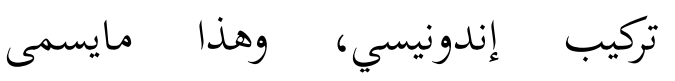
بالتداخل اللغوي. المفروض أن يأني الحال متأخرا لأنه معمول لعامل سابق.

\begin{tabular}{|c|c|}
\hline الصواب & الخطأ \\
\hline إذا أنام بالليل، ثم & إذا أنام بالليل، ثم \\
\hline أنا أستيقظ و & أنا استيقظ و \\
\hline أتذكر، أصلي & أتذكر، مباشرةً \\
\hline مباشرة! & الصلاة! \\
\hline
\end{tabular}

لنرى مثالا آخر من تقديم الحال

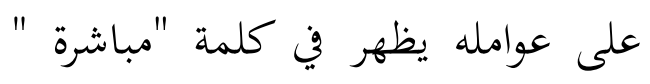

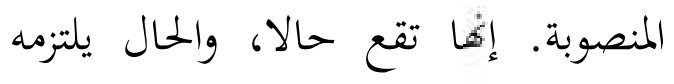
التأخير إلا لعامل على تقديمه ولا يوجد في والسبب ليس بعيدا الجملة عامل عليه. بذلك يكون تأخير "مباشرة" على عواملها واجباً عن الخطأ السابق، وهو استعمال
كما وردت في الجملة، فيلزم من المعطوف

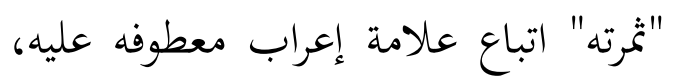
وإذا كان المعطوف عليه مفتوحا فلابد أن أن إنابه يكون إعراب المعطوف مفتوحا أيضا. وأصبحت الجملة الصحيحة " يدرك إكراب الصعاف

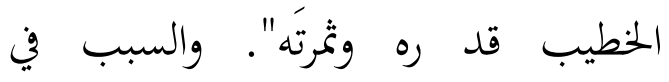
حدوثه يعود إلى عدم معرفة المتحدث لقاعدة المعطوف والمعطوف عليه، وعدم ممارسته في الكلام في سياق العطف. تقديم الحال عن عوامله

\begin{tabular}{|c|c|}
\hline الصواب & الخطأ \\
\hline الرسول -صلى الله & الرسول -صلى \\
\hline عليه وسلم- & الله عليه وسلم - \\
\hline يصلي الليل دائما & دائما يصلي الليل \\
\hline$!$ & ! \\
\hline
\end{tabular}
أن يكون الحال متأخرا من عوامله، كما

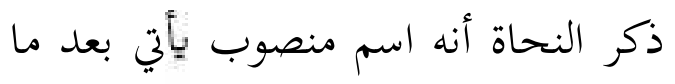

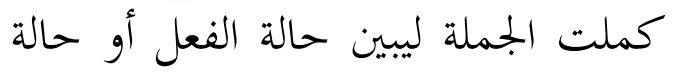
فاعله. أما تقديمه قبل فعله أو فاعله ال

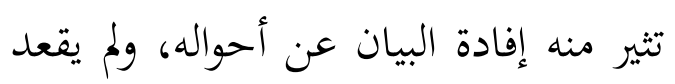


لقد قعّد النحاة قاعدة المضاف

والمضاف إليه ليكون الكلام تاما وليدل على المعنى المفيد. وكذا يغرض من تعقيد القواعد إزالة الإجمام ليتوصل المعنى إلى المستمع أو المخاطب تاما. أما ظاهرة حذف المضاف إليه من غير غرض مخالف للقاعدة، لأنه يذهب الغرض الأساسي للقاعدة وهي إفادة الكلام التام وإفادة إزالة الإمهام .الجملة السابقة في مقام النداء، يعني دعوة المتحدث زملائه ليتقدموا نحو الفصل ليقوموا بالمحاضرة، وعددهم أربعة أنفر. والصحيح أن تكون

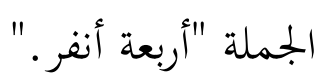

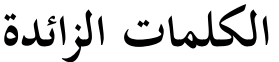

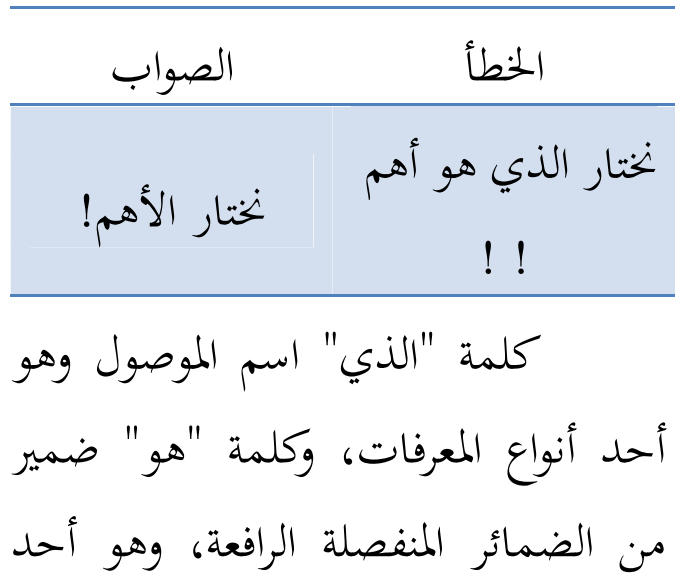

التركيب الإندونيسي في التعبير باللغة

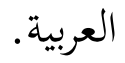

\section{ورود اسم الموصول بعد نكرة}

الخطأ الصواب

نترك شيئا \الني نترك شيئا نحتاج نمتاج إليه!

من أنواع المعرفة أسماء الموصوالت، ورود اسم الموصول بعد النكرة كما ذكر في الجملة عبث، لأن كلمة "شيئا" نكرة، إنما أراد من المتحددث الشيئ المنكور غير المعروف، وإذا جيئت بعد النكرة المعرفة، تذهب منها إفادة النكرة. يلزم من الجملة حذف اسم الموصول لتفيد من الجملة النكرة. والسبب من حدوث الخطأ أن المتحدث يعبر باللغة العربية مستعمال التركيب الإندونيسي. حذف المضاف إليه عمدا الخنطأ

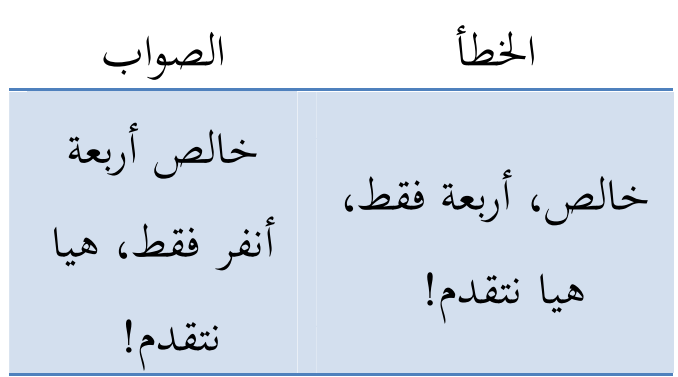


عن..." والسبب فيه عدم معرفة المتحدث التركيب العربي الصحيح.

\section{رفع إعراب المضاف إليه}

\begin{tabular}{|c|c|}
\hline الصواب & الخطأ \\
\hline وبيان حالة & وبيان حالةُ \\
\hline الخطيب، وهو & الخطيب، وهو يعظ \\
\hline يعظ قومه & قومه \\
\hline
\end{tabular}

لنرى مثالا آخر من وقوع الخطأ في خخالفة إعراب المضاف إليه، وهو ظاهر من كلمة "حالة" فإنها مرفوعة بالضمة، إنها وهذا خطأ مخالف لقاعدة الإضافة، المفروض أن تكون مجرورة بالكسرة، لأهما مضاف إليه. والسبب يرجع إلى عدم

\begin{tabular}{|c|c|}
\hline الصواب & الخطأ \\
\hline وخير الهدي, & وخير الهدي', هدي \\
\hline هدي يُجَّة & مُحَّة \\
\hline
\end{tabular}

أن يكون المضاف إليه مجرورا

وعلامة جره كسرة ظاهرة أو كسرتين

ظاهرتين. هذه قاعدة من قواعد نحوية التي قعدها النحاة في باب الإضافة. فيلزم منها
أنواع المعرفات أيضا. ويكون "الذي" و "هو "بجمعين في الجملة متجاورتين، وهذا ما ننقصده بالكلمات الزائدة. ويكون اجتماعهما في الجملة لايدل على معنى معين، بل يذهب عنها روح البالغة،

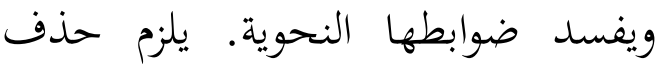
أحدهما أو كليهما، ليكون جليا في تأدية المعنى المراد. أصبحت الجملة" نغتار الأهم". والسبب أن المتحدث محل التركيب الإندونيسي على التركيب العربي. اقتران الفعل بحرف حقه النفراد

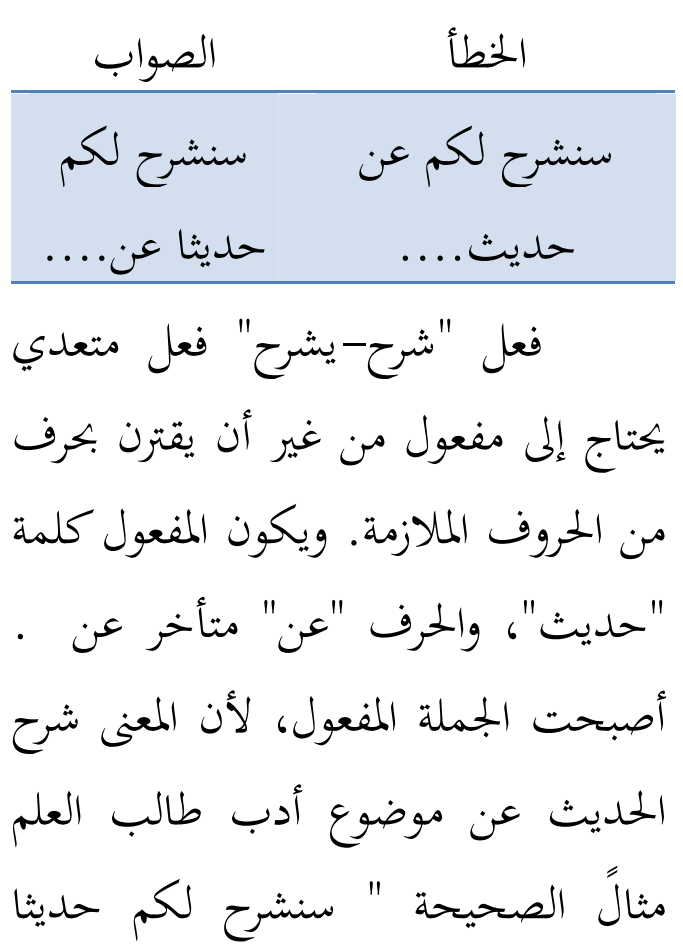


موقع المفعول. وهذا يرجع السبب إلى أن المتحدث حاول أن يعبر باللغة العربية،

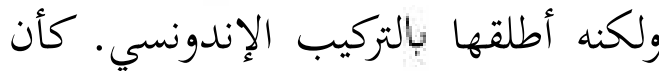
Biar orang awam melihat khotib الجملة " "bagaimana،الإندونيسية باللغة معروفا

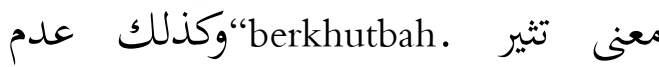
مارسته للكالام الملتزم بالقواعد اللغوية.

\section{دخول ظرف الزمان على اسم الإشارة}

\begin{tabular}{|c|c|}
\hline الصواب & الخططأ \\
\hline لخخبطب لخبط لابد أن & 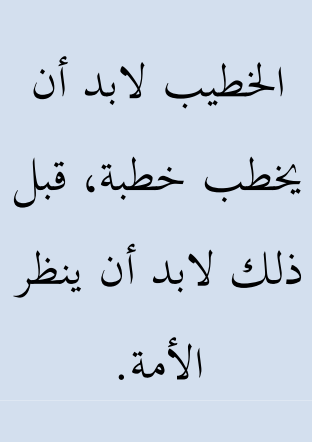 \\
\hline
\end{tabular}

نرى من جملة " قبل ذلك لابد أن ينظر الأمة "، أن "قبل" ظرف من ظروفالزمان وهو أن يكون متأخرا في الجملة ويمكن أن يكون حالاً ولا يدخل على أو تمييزاً أسماء الإشارات، رأينا في الحملة اسم الإشارة "ذلك"، وهما اسمان مخضان لا يقوم بنفسهما إلا إذا اقترنا بعامل آخر، يوحيان
كسر إعراب المضاف إليه في الجملة المكتوبة في المربعوتكون الجملة "وخير" إلئ الهدي ولعل الخطأ سببه يعود إلى عدم معرفة المتحدث بقاعدة الإضافة، وكذا كميةقليلة لتطبيق الكلام باللغة العربية. استعمال أداة "كي" الناصبة وعدم نصب المفعول به

\begin{tabular}{|c|c|}
\hline الصواب & الخطأ \\
\hline كي يرى العوام & كي العوام يرى \\
\hline خطيبا، كيف & خطيب كيف \\
\hline يخطب! & يخطب! \\
\hline
\end{tabular}
الأفعال، ولا تدخل على الأسماء. و وإنما دخلت على الأفعال، وتنصبها. والسبب يرجع إلى استعمال العبارة الإندونيسية وأجروها في اللغة العربية. والسبب الآخر عدم معرفة الطلاب العبارة العربية الصحيحة وعدم معرفة استعمال أداة "كي" الناصبة. ورأينا من الجملة، عدم نصب المفعول به وهو "خطيب"، المفروض أنه منصوب بالفتح، لأنه يقع في 
كلمتي "بلد" و "بلاد" في الإفراد والجمع . وكذا نرى مثلا آخر فيما يتعلق

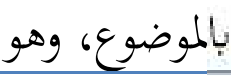

\begin{tabular}{|c|c|}
\hline الصواب & الخطأ \\
\hline أن بلدنا & רו أن \\
\hline أندونيسيا متنوعة & متنوعة القبائل \\
\hline
\end{tabular}

كلمة "إندونيسا" مفرد وإن كان

اسما جنسيا، ولذلك يلزم من كلمة "بلاد "

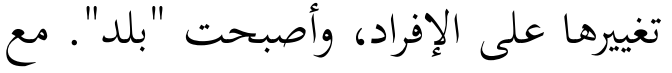
هذا الحكم، أن كلمة "إندونيسيا" حكمت بالتأنيث جوازا. والصواب من التحان الجملة هي نهو، " أن بلدنا أندونيسيا متنوعة القبائل ."والسبب في يرجع إلى أن

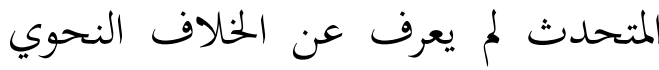

$$
\text { بين كلمتين "بلد" و "بلاد." }
$$

\begin{tabular}{|c|c|}
\hline \multicolumn{2}{|c|}{ رفع اسم لا النافية للجنس } \\
\hline الصواب & الخطأ \\
\hline كما وردت في & كما وردت في \\
\hline الرواية، لا طاعة & الرواية، لا طاعة \\
\hline لمخلوق في & لمخلوق في معصية \\
\hline
\end{tabular}

إلى معنى معين. والصواب من الجملة أن يحذف "ذلك" وأبدل بكلمة أخرى، نحو: بدئه. أصبحت الجملة "قبل بدئه."... جمع الكلمة حقها الإفراد

\begin{tabular}{|c|c|}
\hline الصواب & الخطأ \\
\hline اصنع بهذا البلد & اصنع بهذا البلاد \\
\hline بأخلاق كريمة! & يأخلاق كريمة! \\
\hline
\end{tabular}
كلمة "البلاد" جمع من "بلد" وهو على نوع جمع التكسير. صياغة الجمع الجع تلتزم منها إلحاق حكم التأنيث فيما يتعلق بها من الأفعال أو الضمائر التي ترجع

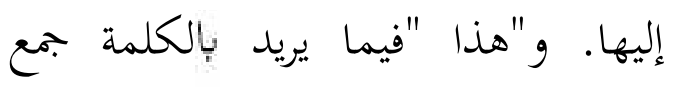

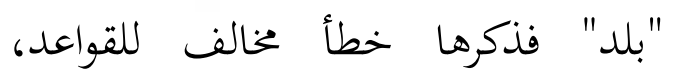
والصواب تأنيث "هذا "فأصبحت الجملة

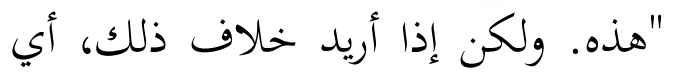

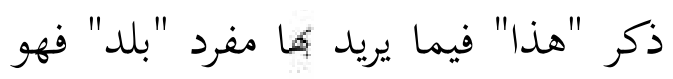
صواب. والمقام في الجملة إيراد "بلاد" مفرده وهو "بلد"، لأن المقام عن اتصاف ببلد إندونيسيا والتحدث عنها، إذن ذكر لهر "هذا" صواب. والسبب في الخطأ يرجع إندان إندان

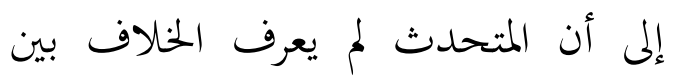




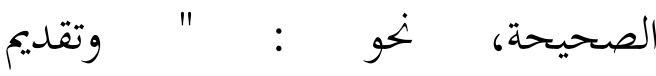

الواجبات....". وهذا يرجع السبب إلى أن المتحدث لم يراعي و يهتم بالكلام مراعاة كبيرة واهتماما جيدا. رفع إعراب المضاف إليه

\begin{tabular}{|c|c|}
\hline الصواب & الخططأ \\
\hline أهم الأمربعد التسامح هو & ألن التسامح هو أهم \\
\hline
\end{tabular}

أن يكون المضاف إليه مجرورا

وعلامة جره كسرة ظاهرة أو كسرتين ظاهرتين ـهذه قاعدة من قواعد نحوية التي قعدها النحاة في باب الإضافة. فيلزم منها كسر إعراب ولعل المضاف إليه في الجملة المكتوبة في المربع. وتكون الجملة " هوأهم

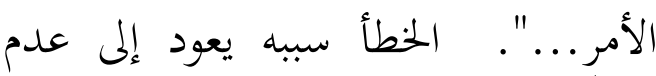
معرفة المتحدث بقاعدة الإضافة، وكذا كمية قليلة لتطبيق الكام باللغة العربية. تأنيث الضمير حقه تذكير الخطأ الصواب أن التسامح هي أهم أن التسامح هو

\section{الخالق معصية الخالق}

حكم لا النافية للجنس أنه يلزم نصب اسمها على الفتح وجوبا. والجملة في المربع السابقة وخاصة في الكلمة "طاعة" أها مرفوعة بالضمة، والمفروض نصبها على الفتح للاتصالها بـ "لا" النافية للجنس. وأصبحت الجملة الصحيحة، لـأل نحو: "لا طاعة.. و والسبب فيه أن المتحدث لم تسب تسبقه معرفة حكم لا النافية للجنس.

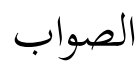
الخطأ وتقديم الواجباتنا نهو وتقديم الواجبات تقديم الوطن ن مو تقديم الوطن كلمة "الواجباتنا" مخالفة للقاعدة، لأكما بتحتمع فيها المعرفتان، ولم يذكر النحاة المعرفات مجتمعة في كلمة واحدة إلا أثها مخالفة عن القاعدة. المفروض أن تأتي الكلمة بواحدة من المعرفتين، إما بـ "ال" نحو "الواجبات"، أم تأتي بالجملة اإضافية، نحو" : واجباتنا". لنأخذ واحدا منهما مثال "ال"، فأصبحت الجملة 
المبتدأ الدقيقة وهي المتعلقة بمجيئ المبتدأ على صورة الجملة. تعريف الكلمة الواقعة مضافا

\begin{tabular}{|c|c|}
\hline الصواب & الخطأ \\
\hline ومن سلبية & ومن السلبية \\
\hline المخدرخصوصا & المخدر خصوصا \\
\hline للطلاب هي : & للطلاب هي : \\
\hline
\end{tabular}

أن يكون الاسم الواقع مضافا نكرة، لأنه أصبح معرفة إذا أضيف إلى الى الى

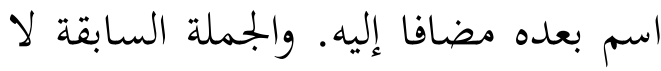
تنوب عن الجملة الإضافية، لأن كلمة "السلبية" دخل عليها "ال" التعريف، فيما يفترض لما عدمه، وأصبحت الجملة شبيهة بالجملة الموصوفية. والصواب من الجملة أن تكون كلمة "السلبية" خالية من "ال"

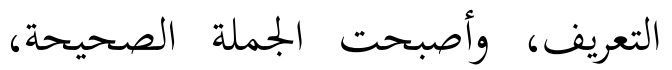

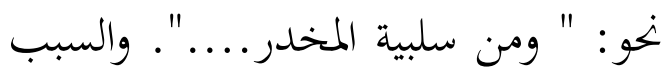
فيه أن المتحدث استعجل في الكلام والنطق بالكلمة حتى أن فقده الالتزام

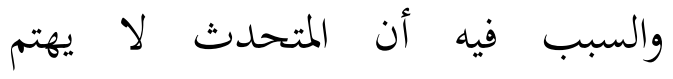
بالقاعدة أي اهتمامه في الكلام وكيفية الإلقاء يسببه إلى عدم مراعته بالقاعدة.

\begin{tabular}{|c|c|}
\hline \multicolumn{2}{|c|}{ نصب إعراب الحخب } \\
\hline الصواب & الخطأ \\
\hline لدى المسلم & لدى المسلم اهتماما \\
\hline اهتمام كبير & كبيرا \\
\hline
\end{tabular}

الخبر اسم مرفوع وقع بعد المبتدأ

ليبين عنه. هذه قاعدة أساسية توضع في بداية كتاب النحو ولابد أن يهتم بها المتعلمون. إلا أن الجملة في المربع السابق

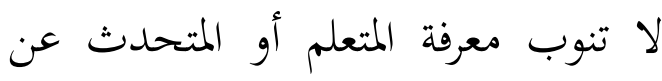
علم النحة المتعلق بباب المبتدأ والخبر. جملة إضافية من "لدى المسلم" مبتدأ في محل رفع، المفروض أن تكون الجملة الآتية خبرا للجملة الإضافية ـوقع المتحدث في هذه النقطة، والصواب منها أن تكون كلمة "اهتمام" مرفوع بالضمة الظاهرة، أصبحت نحو: "لدى المسلم اهتمام....". والسبب فيه أن المتحدث لم يعرف قاعدة لماك اهناف 


\begin{tabular}{cc}
\hline هذه أعمال لتفسد & هذه \\
\hline البلد & العمال تفسد \\
\hline
\end{tabular}

فعل "أفسد- يفسد" فعل متعدي يحتاج إلى مفعول من غير أن يقترن بحرف من الحروف الملازمة. ويكون المفعول كلمة

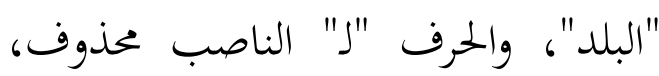
لأن المعنى فساد البلد بسبب الأعمال

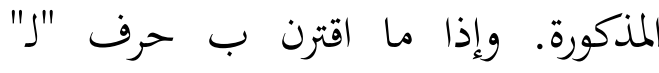
أصبحت لامعنى للجملة ومتناقضقة للمقام. والجملة الصحيحة " هذه أعمال تفسد البلد ". والسبب فيه عدم معرفة المتحدث التركيب العربي الصحيح، واستعماله التركيب الإندونيسي للتعبير باللغة العربية.

نتوصل أخيرا إلى نقاط تحدث ظاهرة الأخطاء الكلامية من كلي المعهدين ، وهذه النقاط نستخلصها في

\section{مخالفة المعطوف إعراب المعطوف}

\begin{tabular}{|c|c|}
\hline الصواب & الخطأ \\
\hline سورة النساء & سورة النساء تسعة \\
\hline تسعة وعشرون & وعشرين \\
\hline
\end{tabular}

وقعت كلمة "تسعة" خبر لجملة

المبتدأ السابقة، وعلامة إعرابه ضمة ظاهرة لأكما اسم ظاهر. ويعطف عليها اسم ظاهر وهو كلمة "عشرين" كما وردت في الجملة، كلمة "تسعة" معطوف عليه،

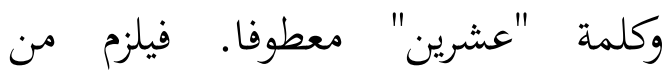
المعطوف اتباع علامة إعراب المعطوف عليه، وإذا كان المعطوف عليه مرفوعا فلابد أن يكون إعراب المعطوف مرفوعا أيضا. وأصبحت الجملة الصحيحة " إسترب سورة النساء تسعة وعشرون ."والسبب في حدوثه يعود إلى عدم معرفة المتحدث لقاعدة المعطوف والمعطوف عليه، وعدم الخاتمة ممارسته في الكلام في سياق العطف. اقتران الفعل بحرف حقه الانفراد عنd 
تأنيث واستعمال الحروف غير المناسبة للكلمة ، عدم المفعول به للفعل المتعدي. المراجع

Ed. Kenneth Croft. 1980. Contrastive Analysis, Error Analysis and Interlanguage : Three Phases of One Goal, (No Place Publication. Jurnal Reading on English as a Second Language for Teacher and Teacher Trainers, edisi 2. Indihati, Dian. 30 Oktober 2014. Pukul, 15.09 WIB. Analisis Kesalahan Berbahasa.

Moleong, Lexy, 2005. Metodologi Penelitian Kualitatif, Bandung: PT Remaja Rosdakarya.

Sudijono, Anas, 1991. Pengantar Statistik Pendidikan, Jakarta: Rajawali Press.

Suharsimi. 1984, Prosedur Penelitian Suatu Pendekatan Praktik, Jakarta: Bina Aksara
التالي : مخالفة النعت للمنعوت ، اقتران الفعل بكرف حقه الانفراد عنهمخالفة المعطوف إعراب المعطوف عليه ، تعريف الكلمة الواقعة مضافا ، نصب إعراب اقتران اسم بحرف حالاً ، رفع إعراب المضاف إليه ، تأنيث الخبر ، رفع اسم إن التوكيد ، الضمير حقه تذكير ، تعدد المعرفات في كلمة ، رفع اسم لا النافية للجنس 6 جمع الكلمة حقها الإفراد ك 6 استعمال أداة "كي" الناصبة وعدم نصب المفعول به 6 دخول ظرف الزمان على اسم الإشارة ، رفع إعراب المضاف إليه ، الكلمات الزائدة ، اقتران الفعل بكرف لـ حقه الانفراد ، حذف المضاف إليه عمدا 6 ورود اسم الموصول بعد نكرة ، تقديم الحال عن عوامله ، تذكير الفعل حقه 